\title{
A Study on Silica and Alumina Potential of the Savannah Bagasse Ash
}

\author{
A. M. Usman, A. Raji, N. H. Waziri and M. A. Hassan \\ Mechanical Engineering Department, Modibbo Adama University of Technology, Yola, Adamawa State, \\ Nigeria
}

\begin{abstract}
This study was carried out to determine silica and alumina potential of ash of sugarcane bagasse obtained from Savannah Sugar Company Numan, Adamawa state of Nigeria. Sugarcane bagasse samples were burnt in a metallurgical furnace at three different temperatures of $500^{\circ} \mathrm{C}, 600^{\circ} \mathrm{C}$ and $700^{\circ} \mathrm{C}$. The percentages of ashes that remained after burning were found to be $12.65 \%, 10.89 \%$ and $9.95 \%$, respectively. The ashes were ground to powder and using X-ray fluorescence (XRF) machine, the samples of the ashes were analysed to determine their percentage chemical oxide composition. The XRF results show that the silica contents are $76.168 \%, 76.292 \%$ and $77.286 \%$ while alumina contents are $11.079 \%, 11.410 \%$ and $10.951 \%$ for $500^{\circ} \mathrm{C}, 600^{\circ} \mathrm{C}$ and $700^{\circ} \mathrm{C}$ respectively. It was concluded that the sugarcane bagasse ash has high silica and alumina total content both of which are the most commonly used reinforcing materials in aluminium matrix composites. It was recommended that to enhance the application of the ash as reinforcement, the ash should be further heated at $1100^{\circ} \mathrm{C}$ and above for a period of $2-3$ hours.
\end{abstract}

Key words: Alumina, Bagasse ash, Composition, Reinforcement, Silica and Temperature

\section{Introduction}

Bagasse is a cellulose fibre remaining after the extraction of the sugar-bearing juice from sugarcane. Biomass is an important source of energy in tropical countries. Bagasse is one of the biomass sources and valuable by products in sugar milling that often uses bagasse as a primary fuel source to supply all the energy needs to power the plants. Burning bagasse as an energy source yields its ash, considered as a waste causing disposal problems. It is well-known that bagasse is an alternative source of energy with high silica content. Several studies have investigated bagasse ash potential applications such as producing silica gel as adsorbent, raw material for ceramic, cements and concrete additives, catalyst, cosmetics, paint and coating, etc. based on its characteristics. The silica contents of bagasse and its ash vary depending on the type of soil, environment and harvesting period and process [1].

According to Aigbodion et al.[2], bagasse is the matted cellulose fibre residue from sugar cane that has been processed in a sugar mill. Previously, bagasse was burnt as a means of solid waste disposal. However, as the cost of fuel oil, natural gas, and electricity has increased, bagasse has come to be regarded as a fuel rather than refuse in the sugar mills.

The sugarcane bagasse consists of approximately $50 \%$ of cellulose, $25 \%$ of hemicelluloses and $25 \%$ of lignin. Each ton of sugarcane generates approximately $26 \%$ of bagasse (at a moisture content of $50 \%$ ) and $0.62 \%$ of residual ash. In order to be used as a mineral the residual sugarcane ash must have appropriate physical and chemical properties [3]. According to Janjaturaphan and Wansom[4], it is common to reutilize sugar cane bagasse as a biomass fuel in boilers for vapour and power generation in sugar factories. Depending on the incinerating conditions, the resulting sugar cane bagasse ash (SCBA) may contain high levels of $\mathrm{SiO}_{2}$ and $\mathrm{Al}_{2} \mathrm{O}_{3}$, enabling its use as a supplementary cementious material (SCM) in blended cement systems.

Several authors from different regions of the world had researched on sugarcane bagasse and its ash and their alternative applications. Among others is Worathanakul et al.[1] who used sugarcane bagasse, from local market and bagasse ash from sugarcane bagasse burnt in factory boilers, the ash was further burnt with and without oxygen for three hours and the burnt ash treated in oxygen with acid and their results show that the silica contents were $75.142 \%, 29.849 \%$ and $89.037 \%$ respectively. According to Affandi et al. [5], different composition of silica xerogels were prepared using three methods. The first methods was pre-treatment of sugarcane bagasse ash using acid washing, the second was re-treatment of the prepared bagasse ash using cation exchange resin and drying while the last method was washing of dried gels using de-mineralized water. Silica was extracted from $10 \mathrm{~g}$ sugarcane bagasse ash using $60 \mathrm{ml}$ of $2 \mathrm{M} \mathrm{NaOH}$ producing sodium silicate. Their results show that the silica content of raw bagasse ash was $50.360 \%$ and for methods $1-3$ were $91.580 \%, 99.37 \%$, 99.160\% respectively. Cordeiro et al.[6] characterised bagasse obtained in stock area and the boiler respectively, of a sugar and alcohol factory situated in the city of São João da Barra Brazil; the silica, alumina and iron oxide contents of the bagasse ash were $78.340 \%, 8.550 \%$ and $3.610 \%$, respectively. Janjaturaphan and Wansom[4] reported the composition of bagasse ash from four different locations as silica: $75.96 \%, 77.21 \%, 75.27 \%$ and 
$74.67 \%$, alumina: $5.32 \%, 4.69 \%, 5.38 \%$ and $4.85 \%$, iron oxide: $2.22 \%, 2.05 \%, 2.54 \%$ and $2.12 \%$, Lime: $3.87 \%$, $3.30 \%, 3.74 \%$ and $3.80 \%$, respectively. Amin[7] reported silica, alumina, iron oxide and lime of $87.40 \%$, $3.60 \%, 4.90 \%$ and $2.546 \%$. Chusilp et. al.[8] reported contents of three different samples of bagasse ash to be silica: $67.10 \%, 76.80 \%$ and $70.18 \%$, alumina: $5.69 \%, 4.40 \%$ and $3.43 \%$, iron oxide: $2.54 \%, 8.04 \%$ and $3.05 \%$ and lime: $2.93 \%, 5.44 \%$ and $7.95 \%$. Srinivasan and Sathiya [9] also used bagasse ash of silica, alumina and iron oxide contents of $78.34 \%, 8.55 \%$ and $3.61 \%$, respectively. Maldonado-Bandala et. al.[10] reported silica, alumina, iron oxide and lime contents of $70.5 \%, 5.23 \%, 3.24 \%$ and $4.19 \%$ while Gandhi [11] reported silica, alumina, iron oxide and lime content of $60.26 \%, 10.73 \%, 5.03 \%$ and $8.35 \%$. Earlier, Muazu [12] reported bagasse ash with $\mathrm{SiO}_{2}-57.95 \%, \mathrm{~A}_{2} \mathrm{O}_{3}-8.23 \%, \mathrm{Fe}_{2} \mathrm{O}_{3}-3.96 \%$ and $\mathrm{CaO}-4.52 \%$.

Researches all over the world today are focusing on ways of utilizing either industrial or agricultural wastes as a source of raw materials for the industry. However, various studies on bagasse ashes have revealed different compositions depending on the sources of the bagasse and hence the need to determine the characteristics of Nigerian bagasse ashes. This work was therefore carried out to synthesize and characterize the Savannah sugarcane bagasse ash obtained under factory processing conditions to determine its silica and alumina contents and its suitability as reinforcement in metal matrix composites. The present research is the first among the series of researches conducted and is aimed at determining the silica and alumina potential in Savannah sugarcane bagasse ash.

\subsection{Materials}

\section{Materials and Methods}

The bagasse was collected from Savannah Sugar Company Numan, Adamawa state of Nigeria. The sugarcane bagasse was obtained directly from processing unit, washed and then dried under sun rays in the factory site. No further treatment was given to the sugarcane bagasse therefore, it was used as supplied from the factory.

\subsection{Equipment and Tools}

The main equipment and tools used in the research include metallurgical furnace, stainless steel crucible, tong, Herzog pelleting machine, somatic C7-621 grinding machine, pellets cups, sample bags, X-ray fluorescence (XRF) machine, sieve, Herzog weighing balance and spoon.

\subsection{Material Burning}

Stainless steel container was used as a crucible to burn the bagasse at temperatures of $500^{\circ} \mathrm{C}, 600^{\circ} \mathrm{C}$ and $700^{\circ} \mathrm{C}$ in a metallurgical furnace, having temperature range of $0-1200^{\circ} \mathrm{C}$, for a period of two hours in the laboratory of the department of Mechanical Engineering, Modibbo Adama University of Technology, Yola. The masses of the bagasse used $\mathrm{M}_{1}$, and ash remain $\mathrm{M}_{2}$ after burning were measured using electric weighing balance and mass loss $\mathrm{M}_{3}$ and their percentages were calculated.

\subsection{Ash Sample Preparation and Chemical Composition Analysis}

The sugarcane bagasse ash was first ground to powder for 60seconds in a somatic C7-621 grinding machine made by Herzog Company Ltd. Thereafter, 20g of the ground bagasse ash samples was mixed with approximately $0.4 \mathrm{~g}$ of stearic acid as flux and binder and put into the grinding machine for another 60s. One third of a pelleting dish was filled with stearic acid while the remaining volume was filled with the ground bagasse ash-stearic acid sample after which it was loaded into Herzog pelleting machine and pelleted at a force of $200 \mathrm{kN}$.

The pellets were then taken to automatic XRF machine for analysis. The pellets were put in a sample pot and arranged in the prescribed positions in the machine, from where the machine automatically picked the pellet samples one by one into the analysis hole and the result of the chemical composition of each sample was displayed after 3 minutes on a monitor of a computer interfaced with the machine.

\subsection{Results}

\section{Results and Discussion}

The masses of bagasse $\mathrm{M}_{1}$, ash remain $\mathrm{M}_{2}$ and losses $\mathrm{M}_{3}$ together with the percentage ash remain and losses are as shown in Table 1 and Fig. 1. The chemical compositions of the bagasse ash at different temperatures are shown in Table 2 while variation of silica and alumina total content and that of the other constituents in the bagasse ash with the temperature of burning are shown in Figs. 2 and 3, respectively. 
Table 1: Masses and percentage of bagasse before and after burning

\begin{tabular}{cccccc}
\hline Temperature & $\mathrm{M}_{1}$ & $\mathrm{M}_{2}$ & $\mathrm{M}_{3}$ & $\%$ Ash & \%Loss \\
\hline 500 & 500 & 59.060 & 440.094 & 12.646 & 87.356 \\
600 & 500 & 54.445 & 445.555 & 10.889 & 89.111 \\
700 & 500 & 49.740 & 450.260 & 9.948 & 90.052 \\
\hline
\end{tabular}

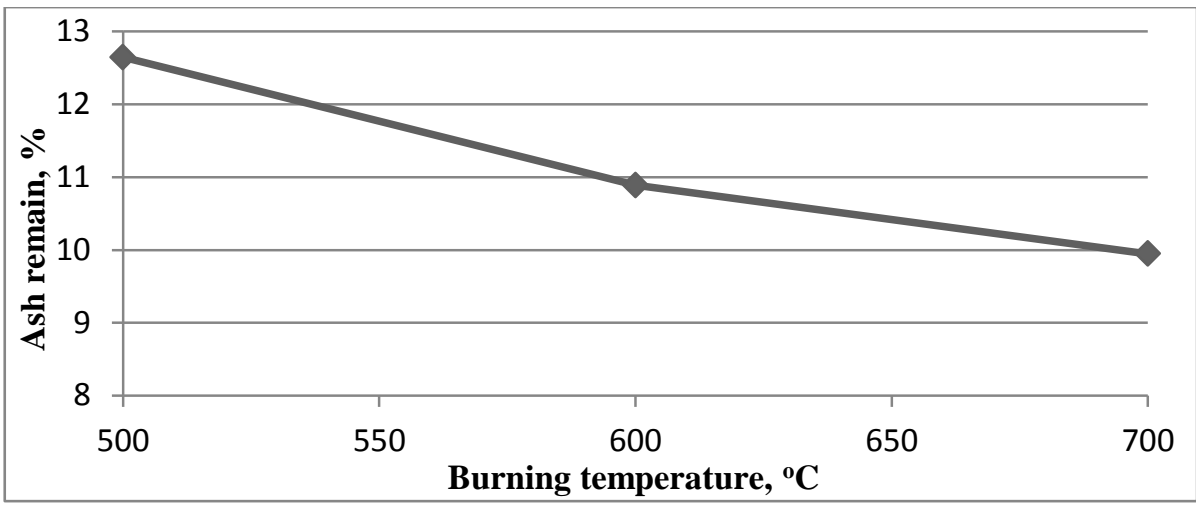

Figure 1: Variation of percentage ash remain after burning with temperature

Table 2: Chemical composition of bagasse ash

\begin{tabular}{c|cccccccccc}
\hline $\mathrm{T}\left({ }^{\circ} \mathrm{C}\right)$ & $\mathrm{SiO}_{2}$ & $\mathrm{Al}_{2} \mathrm{O}_{3}$ & $\mathrm{Fe}_{2} \mathrm{O}_{3}$ & $\mathrm{CaO}$ & $\mathrm{MgO}$ & $\mathrm{SO}_{3}$ & $\mathrm{~K}_{2} \mathrm{O}$ & $\mathrm{Na}_{2} \mathrm{O}$ & Others & LOI \\
\hline 500 & 76.168 & 11.079 & 3.700 & 2.521 & 1.455 & 0.701 & 3.498 & 0.379 & Balance & 3.580 \\
600 & 76.292 & 11.410 & 3.739 & 1.963 & 1.507 & 0.534 & 3.660 & 0.395 & Balance & 3.199 \\
700 & 77.286 & 10.951 & 3.660 & 2.088 & 1.489 & 0.487 & 3.159 & 0.381 & Balance & 3.277 \\
\hline
\end{tabular}

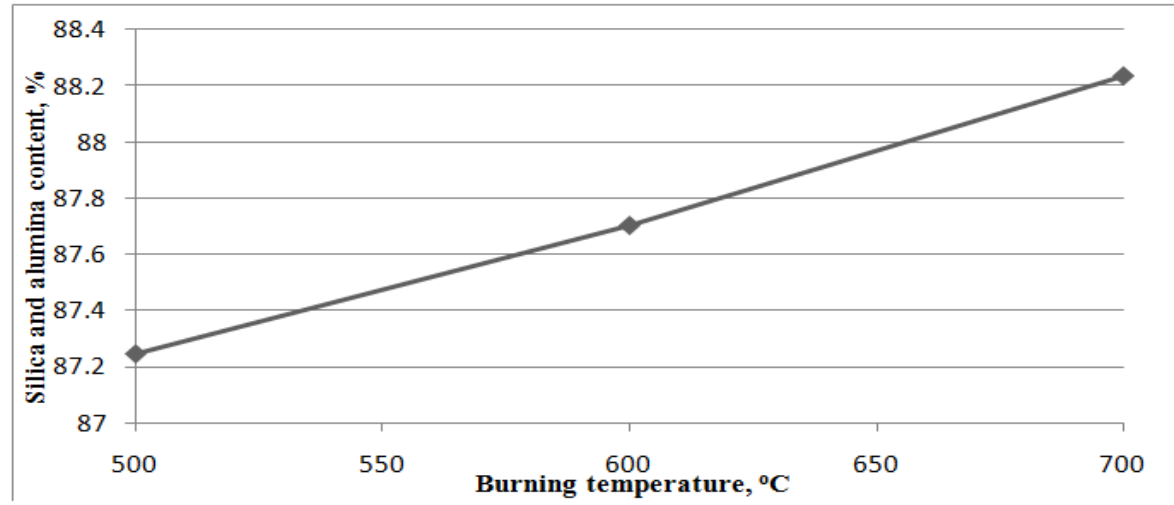

Figure 2: Variation of silica and alumina total content with burning temperature

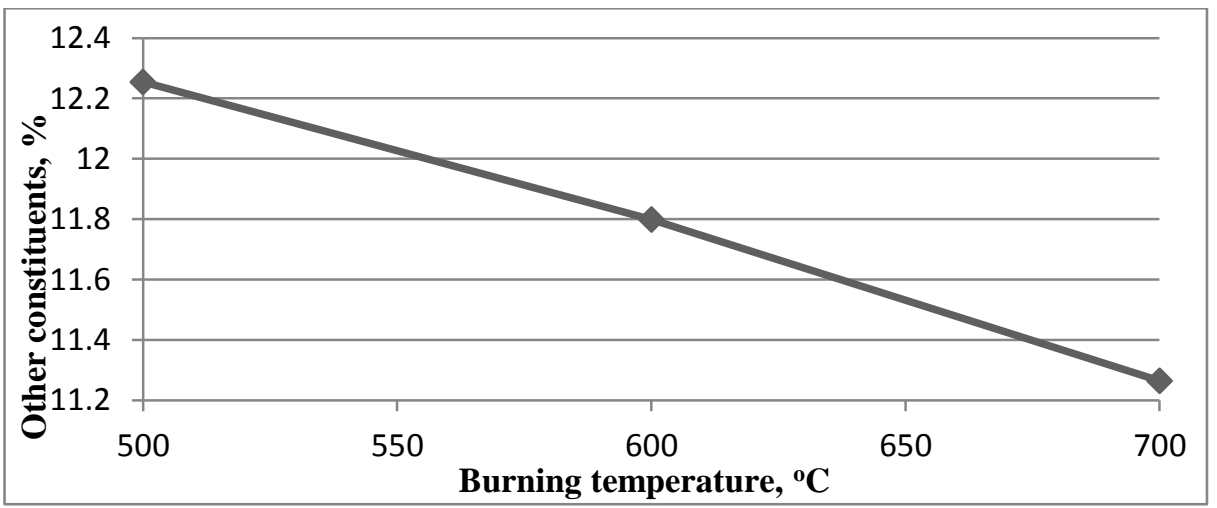

Figure 3: Variation of other constituents in bagasse ash with burning temperature 


\subsection{Discussion of Results}

From the results, the mass of ash remain was highest at temperature of $500^{\circ} \mathrm{C}$ and least at $700^{\circ} \mathrm{C}$. Consequently, the percentage loss at $700^{\circ} \mathrm{C}$ was highest followed by those of $600^{\circ} \mathrm{C}$ and $500^{\circ} \mathrm{C}$. This clearly explains that high quality ash is obtained at $700^{\circ} \mathrm{C}$ due to complete burning leading to loss of all the carbonatious matters in the bagasse and the removal of all the volatile matters without allowing them to react with any material in the bagasse during burning. The silica contents are $76.168 \%, 76.292 \%$ and $77.286 \%$, alumina contents are $11.079 \%, 11.410 \%$ and $10.951 \%$ and iron oxide are $3.700 \%, 3.739 \%$, and $3.660 \%$ at $500^{\circ} \mathrm{C}, 600^{\circ} \mathrm{C}$ and $700^{\circ} \mathrm{C}$, respectively. High quantity of silica and alumina total content in the bagasse burnt at $700^{\circ} \mathrm{C}$ (Figure 2) makes its ash to be high quality.

The results are in agreement and compare favourably with the results reported in Cordeiro et al [6] as $78.340 \%$ and $8.550 \%$ for silica and alumina respectively. The results are also in conformity with some other previous researches in which were reported $74.67 \%-77.21 \% \mathrm{SiO}_{2}$ and $4.69 \%-5.38 \% \mathrm{Al}_{2} \mathrm{O}_{3}$ [4]; 87.40\% $\mathrm{SiO}_{2}$, $3.60 \% \mathrm{Al}_{2} \mathrm{O}_{3}[7] ; 67.10 \%-76.80 \% \mathrm{SiO}_{2}$ and $3.43 \%-5.69 \% \mathrm{Al}_{2} \mathrm{O}_{3}[8] ; 78.34 \% \mathrm{SiO}_{2}$ and $8.55 \% \mathrm{Al}_{2} \mathrm{O}_{3}[9] ; 70.5 \%$ $\mathrm{SiO}_{2}$ and $5.23 \% \mathrm{Al}_{2} \mathrm{O}_{3}[10]$.

However, the obtained results are higher than $60.26 \% \mathrm{SiO}_{2}$ and $10.73 \% \mathrm{Al}_{2} \mathrm{O}_{3}$ reported by Gandhi [11] and $57.95 \% \mathrm{SiO}_{2}$ and $8.23 \% \mathrm{Al}_{2} \mathrm{O}_{3}$ reported by Muazu [12]. The low level of $\mathrm{SiO}_{2}$ and $\mathrm{Al}_{2} \mathrm{O}_{3}$ in bagasse ash obtained in Muazu [12] and Gandhi [11] could be attributed to incomplete burning of the bagasse.

Thus based on the results of the present study, the sugarcane bagasse ash obtained by burning Savannah sugarcane bagasse is capable of having good reinforcing property as it contains high silica and alumina contents with a minimum of $76.168 \%$ and $10.951 \%$, respectively and it could therefore be used in metal matrix composites.

The following conclusions were drawn:

\section{Conclusions}

1. Burning bagasse leads to production of bagasse ash of up to $12.646 \%$ of the mass of the bagasse at $500^{\circ} \mathrm{C}$, $10.889 \%$ at $600^{\circ} \mathrm{C}$ and $9.948 \%$ at $700^{\circ} \mathrm{C}$.

2. Silica contents of the bagasse ash on mass percentage basis were found to be $76.168 \%, 76.292 \%$ and $77.286 \%$ for $500^{\circ} \mathrm{C}, 600^{\circ} \mathrm{C}$ and $700^{\circ} \mathrm{C}$, respectively.

3. Alumina contents on mass percentage basis were $11.079 \%, 11.410 \%$ and $10.951 \%$ for $500^{\circ} \mathrm{C}, 600^{\circ} \mathrm{C}$ and $700^{\circ} \mathrm{C}$, respectively.

4. High quality ash was obtained by burning bagasse at $700^{\circ} \mathrm{C}$ due to complete burning of the bagasse leading to high losses and hence low quantity of ash in the container.

5. Savannah sugarcane bagasse ash has high total content of silica and alumina and could therefore serve as reinforcement in aluminium matrix composites

\section{Recommendations}

1. Practical application of the Savannah bagasse as reinforcement in composites should be carried out to establish its viability.

2. Additional alternative applications of Savannah bagasse ash should be exploited so that the disposal problem will be reduced to bearest minimum.

3. Research to characterise all the bagasse ash of different origins in Nigeria should be done so that the quality of Nigerian bagasse ash will be clearly established.

\section{Acknowledgement}

The authors wish to appreciate the management of Ashaka Cement Plc. and Modibbo Adama University of Technology, Yola for giving them access to their various machines and equipment for the production, preparation and analysis of the ash samples.

\section{References}

[1]. P. Worathanakul, W. Payubnob, and A. Muangpet, Characterization for Post-treatment Effect of Bagasse Ash for Silica Extraction, World Academy of Science, Engineering and Technology, 32, 2009, 360-362.

[2]. S. Aigbodion, S. B. Hassan, G. B. Nyior, and T. Ause, Potential Utilization of Solid Waste Bagasse Ash, Journal of Minerals \& Materials Characterization \& Engineering, 9(1), 2010, 67-77.

[3]. G. C. Cordeiro, R. D. Toledo Filho, E. M. R. Fairbairu, L. M. M. Tavares, and C. H. Oliveira, Influence of Mechanical Grinding on the Pozzolanic Activity of Residual Sugarcane Bagasse Ash, Used of Recycled Material in Building and Structures Conference, Barcelona, 2004, 1-10.

[4]. S. Janjaturaphan, and S. Wansom, Pozzolanic Activity of Industrial Sugarcane Bagasse Ash, Suranaree Journal of Science and Technology, 17(4), 2010, 349-367. 
[5]. S. Affandi, H. Setyawan, S. Winardi, A. Purwanto, and R. Balgis, A Facile Method for Production of High-Purity Silica Xerogels From Bagasse Ash, Advanced Powder Technology, 20, 2009, 468-472.

[6]. G. C. Cordeiro, R. D. Toledo Filho, and E. M. R. Fairbairn, Ultrafine Sugarcane Bagasse Ash: High Potential Pozzolanic Material For Tropical Countries, Ibracon Structures and Materials Journal 3(1), 2010, 50-67.

[7]. N. Amin, Chemical Activation of Bagasse Ash in Cementitious System and its Impact on Strength Development, Journal of Chemical Society Pakistan, 32(4), 2010, 481-484.

[8]. N. Chusilp, N. Likhitsripaiboon, and C. Jaturapitakkul, Development of Bagasse Ash as a Pozzolanic Material in Concrete, Asian Journal on Energy and Environment, 10(3), 2009, 149-159.

[9]. R. Srinivasan, and K. Sathiya, Experimental Study on Bagasse Ash in Concrete, International Journal for Service Learning in Engineering, 5(2), 2010, 60-66.

[10]. E. E. Maldonado-Bandala, V. Jiménez- Quero, F. J. Olguin-Coca, M. L. G. Lizarraga, M. A. Baltazar-Zamora, C. A. Ortiz, C. F. Almeraya, R. P. Zambrano, and C. Gaona-Tiburcio, Electrochemical Characterization of Modified Concretes with Sugar Cane Bagasse Ash, International Journal of Electrochemical Science, 6, 2011, 4915-4926.

[11]. K. S. Gandhi, Expansive Soil Stabilization Using Bagasse Ash, International Journal of Engineering Research \& Technology, 1(5), 2012, 1-3.

[12]. M. A. Muazu, Influence of Compactive Effort on Bagasse Ash with Cement Treated Lateritic Soil. Leonardo Electronic Journal of Practices and Technologies, 10, 2007, 79-92. 